\title{
The Creativity Training Discussion of Microcontroller Technology Applied Talents
}

\author{
Wei Wei \\ Wuhan City Vocational College, Wuhan, Hubei province, China
}

Keywords: SCM technology, applied talents, innovation ability, training

\begin{abstract}
In recent years, with the rapid development of the social economy and the in-depth adjustment of the industrial structure, the society increasingly needs professional talents that can adapt to the direction of industrial restructuring. In order to better adapt to the needs of industrial restructuring, this article explores the application of SCM technology in terms of professional training objectives, teaching models, curriculum systems, training conditions, and assessment methods based on the characteristics of the application of single-chip microcomputer technology, to cultivate talents that are more in tune with local socio-economic development and better serve the local economy.
\end{abstract}

\section{Introduction}

In recent years, with the rapid development of China's socialist modernization drive, China has entered a crucial period of structural adjustment and development. Therefore, the adjustment and upgrading of the industrial structure is a major issue facing China's social and economic development at the current stage. The demand for industrial talents from enterprises is constantly increasing. This will inevitably require corresponding adjustments in the training objectives of vocational education. As a teacher engaged in the application of electronic specialty teaching in higher vocational colleges, how to adapt to the development requirements of the national industrial structure adjustment and upgrading, what kind of application of electronic professional personnel training is an urgent need to study the reform and solve the problem [1]. Through the company's research, it analyzes the occupational positions of relevant companies, and plans to make corresponding adjustments to the training objectives, teaching models, curriculum systems, training conditions, and assessment methods of the applied electronic specialty when formulating the personnel training program.

\section{The lack of single-chip microcomputer talents training}

The survival of the fittest is an objective law in nature. To adapt to the market, it is necessary to stand in the perspective of market demand and re-examine the teaching, experiment, and related curriculum settings of the SCM course.

\subsection{MCU teaching materials and teaching methods need improvement}

Throughout the current popular college single-chip teaching materials, have their own focus, have reference value. In general, there are many basic principles, and there are few application examples [1]. Even if there are some application examples, there are many obsolete devices, and the information that is still obsolete is still used; the weight of the verification principle is heavy and has practical weight.: Some textbooks have a long history of duplication or publication. Although the basic principles of the SCM are still applicable, the peripheral devices and interface technology have undergone tremendous changes, and the knowledge of books has lagged far behind.

The teaching of SCM is characterized by strong practicality and strong practicality. It is quick to use effective examples and examples of teachers to promote teaching [1]. Just like learning to swim, it is much better to demonstrate in the pool than to explain it on the blackboard. 


\subsection{Supporting discipline construction needs to be strengthened}

The SCM course is not an isolated subject and must be supported by supporting technologies. The most important of these are "digital circuits", "integrated circuit application technologies", "professional English", "computer principles and interface circuits", "assembly language", "C language", "circuit design CAD" and "EDA", etc. At present, our school has opened these courses and the basic conditions are already in place [1]. However, we need to further guide students in the application of practical activities to integrate the above scattered and independent knowledge, integrate them into one, and apply them to the selection of topics, proposals, and layouts. Software programming and whole board debugging go through the whole process. Students have the ability to work, have an innovative spirit, and have a competitive edge in the talent market.

\subsection{SCM experimental equipment needs improvement}

The status quo of the SCM experimental equipment is not optimistic. Because the information we collected is not comprehensive enough, we dare not take a point of view. However, the products of the four major SCM equipment suppliers in China have all been tried, mostly three or five years ago. The introduction is old equipment and even some earlier. These devices are basically matched with the early teaching materials [2]. The experimental contents are outdated. The purpose of the student experiments is mainly to verify the principle of the books. Only the programs can be modified and the wiring can be changed within the scope of the fixed experimental topics. The opportunities for the students to use their brains and hands are too great. In addition, the experimental devices are mostly a platform that integrates more than a dozen experimental topics [2]. The structure is complex, and equipment manufacturers are reluctant to provide complete circuit design drawings. Students are unable to digest and understand the experimental principles. In the experiment, temporary wiring is required, and the connector is easy to loosen, and the experimental result is unstable.

\section{The cultivation of innovative talents of SCM technology application talents}

\subsection{Training target positioning}

Master the basic theory and basic skills necessary for the application of single-chip microcomputer technology, have a certain ability to analyze and solve the practical problems of the single-chip microcomputer; understand the new technology, new technology and new knowledge of the single-chip microcomputer; engage in intelligent electronic products in the electronic information manufacturing industry Design, production, testing, maintenance, management and sales work; there is a certain ability of engineering practice design, able to adapt to socio-economic development of skilled technicians [2].

\subsection{Teaching model positioning}

Use a variety of teaching models to achieve these goals.

1) Pursue "school-enterprise cooperation and work-study integration". It promotes the "school-enterprise cooperation, work-study combination" teaching model, and cooperates with enterprises to create "engineering innovation training center", introduces the company's technology and management methods, and places interest classes and innovation centers [2]. The three-combination of practice bases will improve students' practical ability and innovation ability, and at the same time enable students to experience the management concepts of modern enterprises in the actual learning environment and combine the 6S management standards in the enterprise to cultivate good professional habits; to understand or master The new technology, new technologies and new theories of the SCM technology will cultivate cognitive and practical capabilities.

2) Implement teaching as the "six matching" teaching mode of integrated reality and practice. Actively implement the "six matching" mode of integration and integration of talents, the connection between talent training specifications and the job requirements of the company, the connection between the role of the teacher and the role of the master, and ideological quality the docking of education and vocational cultural literacy, the docking of teaching content with production projects, 
the docking of competency assessment and corporate evaluation, and the connection between training environment and corporate culture [2]. The school employs skilled craftsmen to provide on-site instruction to students in the production process of modern intelligent electronic products, to understand the new technologies applied in modern intelligent electronic products, and to create real training opportunities for students. In order to improve the ability to apply technology, enhance self-discipline, service awareness, sense of responsibility in work, to develop punctuality, fast-paced, rigorous and professional professionalism, improve students' comprehensive professional ability and employment competitiveness, and to achieve seamless linkage between school-enterprise training "Zero adaptation period" technical and skilled personnel.

3) Using scientific research projects to promote the teaching mode. Encourage teachers to actively participate in the cooperation of enterprises to carry out research and promotion of the application of electronic products and electronic new technologies [3]. Actual products are used as projects to stimulate students' interest in learning and guide student participation. Projects are able to develop students' ability to think independently, their ability to solve problems, and their ability to practice innovation.

\subsection{Course system construction}

The application of single-chip microcomputer technology is a wide-caliber professional, with more branches and different school. It is necessary to combine service-related industries with local economies. It should be a breakthrough in the direction of professional integration and be integrated with the modularization of curriculum systems [3].

According to the above ideas, the teaching content of the application of SCM technology is divided into three modules: professional basic course modules, professional modules and professional direction modules.

Professional basic course module: Contains knowledge of electronic components, circuits, measuring instruments and computer programming, such as: circuit analysis, microcontroller technology, microcontroller technology, electronic design technology, computer programming technology, measurement technology, data acquisition technology, etc. The basic knowledge of SCM technology has been mastered in the course of professional basic courses [4]. At the same time, this foundation has provided the impetus for the sustainable development of students. In this phase of the curriculum implementation process, the ratio of theory and practice is 6:4.

Professional module: This module highlights the characteristics of practicality, practicality, and comprehensiveness. It closely follows the new trends of intelligence, networking, and informatization. With projects as the carrier, the program must embody the most advanced courses in the existing single-chip microcomputer technology. Such as smart card technology, SOPC programming technology, ARM embedded technology, DSP application technology, network technology, etc., in the specific teaching implementation process, the introduction of the project, process and assessment should be closely integrated, so that the integration of reality, to achieve teaching triple [4].

Professional orientation: It embodies the characteristics of professional leading-edge and advanced, and takes the form of public lectures and special reports as the carrier of professional courses. It introduces the new technology, new technologies and new knowledge of SCM technology. Through the teaching of professional orientation courses, students are allowed to understand the latest developments in the profession and provide a clear direction for student learning.

\section{Cultivation of practical innovation ability}

Practical teaching is an important place for the cultivation of professional education practice ability. Due to the development of modern technology, the conditions for training outside the school are transferred to the school. Through the form of school-enterprise cooperation, the "Innovation Training Center for Engineering Practice” is jointly established. The practical courses are divided into three levels: basic skill training, vocational skills training, and comprehensive professional ability training [5]. Professional skills and comprehensive skills should closely follow the actual 
development and changes in production of enterprises, and fine-tune teaching content in accordance with the development of professional and technical fields to ensure that the curriculum system is professional, timely, and timely.

\subsection{Practice training stimulates students' enthusiasm for innovative practice}

In order to cultivate the comprehensive practice design ability and sense of innovation of the students of automation majors, improve the students' understanding of the profession, quickly adapt to the open, self-study learning mode of the university, and make the laboratory a practical base for innovative talent training and excellent engineer training [5]. Through training, students have an understanding of innovation, established a sense of innovation, thought of how to innovate, and broadened the scope of knowledge for innovation, not just the current textbook knowledge. Introduce the basic knowledge about the one-chip computer initially; make the student have a preliminary understanding to the application of the one-chip computer, lay the foundation for the further study of the student.

\subsection{Reform teaching mode to cultivate students' practical ability}

The theory and practice of single-chip microcomputer technology is a practical and integrated course. It completes teaching and practice in the laboratory and realizes learning and learning while doing. Teachers integrated the curriculum content, divided the curriculum into eight knowledge modules, and integrated theoretical teaching into practice [5]. For example, the knowledge module C language intensive training is not boring programming language teaching, but the program design knowledge into the microcontroller I / O port applications (water lights, flashing lights, decorative advertising lights, etc.), digital control and keyboard operation practices During the learning process, the goals are clearly reachable, easy and interesting, vivid, and vivid.

\subsection{Promote practice and innovation capability with competition promotion}

Actively implement the national plan of excellence, provide a wide range of open experimental platforms, coupled with excellent teachers, encourage students to actively participate in intramural and off-campus competitions, adhere to the "to promote learning through competition," and strengthen the cultivation of students' engineering capabilities and innovation capabilities [6]. Automated students benefit from summer training after entering the school, enabling them to better invest in engineering application abilities and get access to professional knowledge sooner.

The large number of high-level student science and technology works and achievements that emerged in the competition and innovative education practice are very persuasive to students, stimulating students' interest in learning, self-confidence and initiative. Through the help of senior students in the help, teaching, and teaching of the younger students, they can quickly integrate into the innovation practice and at the same time bring innovative education into the right track and form a virtuous circle.

\subsection{Corporate exercise improves students' engineering practice ability}

During the implementation of the plan for excellence, the school will construct laboratories, training bases, and engineering practice centers, introduce some equipment used in the actual practice of the company, and strive to conform to the actual industrial environment, but still exist in disproportion with the enterprise in varying degrees. The graduates lacking school-enterprise cooperation cannot adapt to the work of the company immediately. School-enterprise cooperation will provide students with the opportunity to understand familiarize with and master the most advanced production equipment and manufacturing technology of the company [6]. After graduating, they will become "quick-starting" engineering talents who are generally welcomed.

The college and industry companies have in-depth cooperation to build a base for practical education outside colleges and universities. They jointly design specification requirements for determining engineering practice abilities, clarify the requirements and tasks of the curriculum, and send students in the seventh semester to send them to cooperative companies for internships to accept corporate engineers. Training, assist engineers to complete related work, and complete the graduation 
design task under the guidance and guidance of the enterprise engineer.

\subsection{Reform assessment methods}

The assessment method is of great significance to the quality supervision of vocational education. According to different teaching modules, a dynamic assessment method is proposed. The proportion of written examinations and interviews varies with different teaching modules. When conducting professional basic curriculum module learning, assessment The written test is mainly based on the interview. The total score is composed of the usual results, written test scores and interview results [6]. The professional module is mainly based on interviews, written on related theoretical knowledge; professional orientation courses are submitted in the form of submitted papers, interviews are mainly practical operation examinations; usually results are evaluated by process evaluation (20\%) + teacher-student mutual evaluation (10\%) + professional teachers and professional experts (20\%), to make the process and results important at the same time, to overcome the student's heavy results, not the process, the theory does not emphasize the practice. Throughout the assessment process, the separation of teaching and examination should be carried out to separate the identities of the athletes and coaches, to achieve effective monitoring of teaching quality, and to improve the quality of teacher education and student learning.

\section{Summary}

Today, with the rapid development of science and technology, the development speed of computer technology and its related integrated circuits is in a leading position. All walks of life are eager to use computer technology and the latest integrated circuits to arm themselves and promote product replacement. Today, computer technology is divided into two branches in the development direction: general computer technology and embedded special computer technology. By embedding single-chip microcomputers in products and developing modern equipment and products with artificial intelligence, it becomes the goal pursued by entrepreneurs and a way to make money. As a branch of computer application technology, single-chip microcomputer plays an important role in the development of intelligent products, and has a great influence and dependence on the market. The teaching of the single-chip microcomputer curriculum is closely related to the market demand. The teaching content and teaching methods are only reformed.

\section{Acknowledgement}

Fund project: Wuhan city Colleges and universities production research project of 2016 Wuhan Education Bureau. (Project ID: CXY201638).

\section{References}

[1] J.M. He, Exploration of Curriculum Setting of Applied Electronic Specialty in Higher Vocational Education, Journal of Shangqiu Teachers College, 2006, vol.2, pp.21-23.

[2] Z.J. Li, Curriculum Setting under the Credit System of Higher Vocational Education, Border Economy and Culture, 2008, vol.11, pp. 34-37.

[3] Y.T. Gao, Study on Curriculum Design of Computer Specialty in Higher Vocational and Technical Colleges in Liaoning Province, Shenyang Normal University, 2008, pp. 15-18.

[4] M.D. Wu, Exploration of Higher Vocational Education Curriculum and Curriculum Setting, Science Educator, 2008, vol.12, pp. 66 - 69.

[5] G.T. Lin and J.T. Bao, Professional Setting and Curriculum Development of Higher Vocational Education, Beijing: Higher Education Press, 2004, pp. 43-47.

[6] J.F. Gao, On the cultivation of electronic specialty in higher vocational education, Online Education Forum, 2010, vol. 3, pp. 5-7. 